\title{
Asymmetric price transmission in the Spanish lamb sector
}

\author{
M. Ben-Kaabia, University of Zaragoza
}

José. M. Gil, CREDA-UPC-IRTA, Barcelona

Received June 2006, final version received January 2007

Acknowledgements:

The authors would like to thank the referees and the editor of the journal for helpful comments on earlier drafts. We take the responsibility for any remaining errors and omissions.

Corresponding author: José. M. Gil

CREDA-UPC-IRTA, Edifici ESAB - Parc Mediterrani de la Tecnologia

Av. del Canal Olimpic s/n, 08860-Castelldefels (Barcelona)

Ph: ++34-935521210, Fax: ++34-935521121

e-mail: chema.gil@upc.edu 


\title{
ASYMMETRIC PRICE TRANSMISSION IN THE SPANISH LAMB SECTOR
}

\begin{abstract}
This paper investigates the non-linear adjustment of prices between farm and retail prices in the lamb sector in Spain, using a three-regime Threshold Autoregressive Model. The results indicate that, in the long run, price transmission is perfect and any supply or demand shocks are fully transmitted along the marketing chain. In the short run, price adjustments between the farm and the retail levels are asymmetric and reveal a demand-pull transmission mechanism. On the other hand, retailers benefit from any shock, whether positive or negative, that affects supply or demand conditions.
\end{abstract}

Keywords: Asymmetries, non-linear adjustments, lamb prices, Spain

JEL Classification: C32, L11, Q11, Q13

\section{$1 \quad$ Introduction}

The issue of marketing margins and price transmission along the food chain has attracted considerable research interest among agricultural economists, as it has long been considered relevant to Structure, Conduct and Performance (SCP) analyses. In the last two decades, the number of studies on this subject has grown sharply in response to concerns that rapid changes in markets and business practices could generate potentially important welfare and policy implications. It is commonly felt that retail prices do not react very quickly to changes in market conditions. A good example is where retail prices remain sticky although input prices have fallen due to primary production increases (Peltzman, 2000). In this situation, the retail price is equal the marketing clearing price, thus generating excess supply, and consumers do not benefit from declining farm prices, with implications for consumer welfare. Policy makers are also concerned about the extent to which consumers benefit from a reduction in farm prices as a consequence of agricultural policy reform.

However, as Vavra and Goodwin (2005) pointed out, although the evolution of margins over time and price transmission have been considered jointly in the literature, they are different 
topics, and their analysis provides information on different, although complementary, questions. Many empirical studies have been concerned with the determinants of marketing margins and price spreads along the food chain, leading authors to use structural models (Gardner, 1975; Cowling and Waterson, 1979) under some restrictive assumptions (constant returns to scale, perfect competition and fixed-proportions production technology). Recently, a number of studies have developed a new theoretical background in order to allow for the presence of market power and returns to scale and their impact on price adjustment processes (McCorriston et al., 2001; Sexton et al., 2003; Lloyd et al., 2006) ${ }^{1}$. Although structural models are better at finding explanations for imperfections in price transmission, in most papers there is a gap between the theoretical model and the empirical application, as some of the marketing margin determinants are unobservable.

Partly for this reason, much of the empirical literature dealing with price transmission has been concerned only with applying time-series modelling techniques to price data. The main focus of this approach has been to characterise vertical price relationships by the extent, speed and nature of the adjustments via the supply chain to market shocks generated at different levels in the marketing process. Thus, it complements the marketing margin models, which are mainly concerned with testing for market imperfections and calculating the price transmission elasticity. Particular importance has been given in recent research to the question of asymmetry of price adjustments. When based only on price data, the main shortcoming of asymmetric price transmission studies is the lack of empirical tests to explain any imperfections found. However, since in most empirical analysis different structural stories may be consistent with the results obtained, an understanding of the fundamental structure of the markets under consideration is essential for a proper interpretation of the results (Goodwin, 2006).

The empirical literature offers alternative explanations for asymmetric price adjustments ${ }^{2}$ : market power at the retail level ${ }^{3}$ (e.g. Boyd and Brorsen, 1988; Griffith and Piggott, 1994, and

\footnotetext{
${ }^{1}$ A review of the empirical issues underlying this literature can be found in Wohlgenant (2001).

${ }^{2}$ See Meyer and von Cramon-Taubadel (2004), Weldegebriel (2004) and Frey and Manera (2007) for a comprehensive review of the literature dealing with potential causes of asymmetries in vertical price transmission.
} 
Bettendorf and Verboven, 2000), adjustment costs at the retail level (Chavas and Mehta, 2004), input substitution at the processing level (Bettendorf and Verboven, 2000), stocks at both the production and retail level (Reagan and Witzman, 1982), and public intervention (Kinnucan and Forker, 1987). However, in only a few cases (e.g. Peltzman, 2000) statistical tests have been carried out to link asymmetries with any of these potential explanations.

Despite the many studies that have investigated vertical price adjustment processes along the food chain, results from the empirical literature are inconclusive. Studies generally differ in terms of the goods analysed, countries, time frequencies, time periods and model specification (Frey and Manera, 2007). Consequently, it is difficult to draw conclusions on which to base policy decisions (Vavra and Goodwin, 2005).

Against this background, the aim of this paper is to investigate the asymmetries in the price transmission mechanism between farm and retail marketing channels in the Spanish lamb market. In particular, we focus on four issues: 1) the size of the price response at each end of the supply chain to a shock of a given size at the other end; 2) the speed and profile of the response; 3) whether responses are symmetric or asymmetic; 4) whether adjustments differ depending on direction (i.e., for shocks transmitted backwards or forwards along the supply chain).

A Threshold Vector Error-Correction Model (TVECM) and the corresponding non-linear impulse response functions are presented. This methodological approach has been proved to be flexible enough to deal with the specific questions raised above. Moreover, it allows us to

${ }^{3}$ Although asymmetries have been linked to non-competitive behaviour, this is not necessary. McCorriston et al. (2001) showed that, in the presence of market power, price changes could be greater or less than the competitive benchmark case depending on the interaction between the market power and returns to scale. If the industry is characterised by decreasing returns to scale, the damping effect of market power is reinforced. On the other hand, if it is characterised by increasing returns to scale, the market power effect is offset. Weldegebriel (2004) concluded that the functional forms of retail demand and farm input supply are key factors in determining the level of price transmission and that the presence of market power does not necessarily mean imperfect price transmission. Finally, Azzam (1999) showed that retail prices might react more to a positive shock to producer prices than to a negative shock, generating asymmetries even in a competitive environment. 
test for the presence of non-linear adjustments in the price transmission mechanism commonly associated to menu costs. Although this approach is not new in the literature, this paper makes three key contributions. First, it exhaustively explores all empirical possibilities the analytical tool provides, paying special attention to statistical tests for correct specification. Second, the paper presents the regime-specific short-run dynamics, which have not been previously considered. Finally, it is the first attempt to analyse the vertical price linkages in the Spanish lamb markets. In this context, results will be discussed taking the specific characteristics of the Spanish lamb sector into account.

The rest of the paper is organised as follows. In Section 2, the main characteristics of the Spanish lamb sector are described, including some potential explanations of non-linearities. Section 3 presents a description of the methodological approach used in the paper. Section 4 deals with some preliminary data analyses while Section 5 reports our empirical results. Finally, Section 6 closes the paper with some concluding remarks.

\section{The Spanish lamb supply chain and potential sources of asymmetries}

Spain is the second largest lamb producer in the European Union (EU) just behind the United Kingdom. It represents around 5 per cent of Spain's final agricultural production and 11 per cent of final livestock production. Moreover, lamb production plays a key economic role in rural areas: it is one of the few output options in arid areas, and 80 per cent of the total production is located in Less Favoured Areas (LFAs).

Since the introduction of individual quotas in 1992, ewe numbers have been effectively stabilised throughout the Union as a whole. In Spain, breeding ewe numbers increased from 18.3 million in 1992, only to 18.5 million in 2000. Between 1990 and 2002, the number of slaughterings increased by 4 per cent to reach 20 million heads, while total meat production increased by 7.5 per cent to 221,000 tons. A specific characteristic of the Spanish lamb sector is that the average carcass weight is well under the EU average of $14.5 \mathrm{~kg}$ : nearly one quarter of slaughtered animals have a carcass weight lower than $10 \mathrm{~kg}$ (averaging just $7 \mathrm{~kg}$ ), while for the rest the average weight is $12.6 \mathrm{~kg}$. This is due to both to the breeds reared and to consumption habits, as Spanish consumers have strongly prefer younger animals with low fat and rose-coloured meat.

Although the Common Market Organisation operating rules in force during the period studied may have influenced the movement of sheep on or off a holding, they did not prevent 
producers adapting production to meet consumer preferences. However, the way the premium was calculated ${ }^{4}$ may have dissuaded producers whose flocks produced fewer lambs per ewe than the average from responding to market signals. In fact, as the premium paid declined as market prices rose, these flocks risked an income decline at higher prices per lamb. Conversely, however, because the premium was equal for all ewes, individual producers who achieved better than average market prices through improved quality or other market initiatives, and who produced more lamb per ewe than the average, could achieve higher margins. Consequently, farmer prices were not primarily determined by the ewe premium and producers had incentives to adapt to changing market conditions. In this context, it is not expected that public intervention was a potential cause of asymmetric price transmission along the Spanish lamb supply chain.

Figure 1 shows the evolution of weekly farmer (FP) and retail (RP) prices in the period 19962002. Farm prices are from the Spanish Ministry of Agriculture, Food and Fisheries (MAPA) ${ }^{5}$. Retail prices come from the Boletín Económico del ICE (Ministry of Economic Affairs $)^{6}$.

${ }^{4}$ The premium awarded annually to EU sheep producers was calculated as follows. First, the European Council decided a basic yearly price, which was thought to give a reasonable income to producers. Second, the Commission calculated a single market price using national prices weighted according to Gross Domestic Production (GDP). Income loss was determined as any difference, per $100 \mathrm{~kg}$ carcass weight, between the basic and the market prices. As the premium was awarded on a per ewe basis, a technical coefficient (the ratio between the number of heavy ewes and the production of heavy lambs expressed in kilos) was used to translate the premium to a per ewe figure.

${ }^{5}$ The farm price is a weighted average of the five most representative markets in Spain (Ebro, Talavera de la Reina, Zafra, Albacete and Medina del Campo). These unpublished price data were sent to Brussels in order to obtain the European representative market price for lamb to calculate the ewe premium. We are grateful to the Spanish Ministry of Agriculture for permission to use these data.

${ }^{6}$ Original retail prices are expressed in $€ / \mathrm{kg}$ of a specific lamb cut (leg). In order to make retail prices comparable to farm prices and to calculate marketing margins, we have used a conversion factor of 1.2 to express the retail price in $€ / \mathrm{kg}$ of carcass weight. 
(Insert Figure 1)

Producer and retail prices exhibited a similar trend and a common seasonal component, which is more evident at the retail level. It can be seen that the retail price tended to react slightly later than the farm price when faced with changing market conditions.

Figure 2 shows the evolution of the retail marketing margin both in absolute values (Figure 2a) and as a percentage of the farm price (Figure 2b). While in the first case the marketing margin exhibits an upward trend, percentage changes have been quite stable on average (around 90 per cent of the farm price) during the period analysed, although it seems that volatility increased slightly. It also shows a strong deterministic component at the end of each year due to consumption habits.

\section{(Insert Figure 2)}

By construction, the evolution of marketing margins is related to changes in farm and retail prices. However, by visual inspection of Figures 1 and 2, the nature of this relationship is not clear enough. Therefore, we divided the sample period into two sub-periods depending on whether the relative marketing margin (Figure 2b) was increasing or decreasing. Then, we calculated the weekly average percentage change in farm and retail prices in each sub-sample to obtain, although very roughly, some indication about potential asymmetric behaviour (Figure 3). We note three main results. First, changes in marketing margins are primarily due to changes in farm prices (increases in farm prices squeeze the marketing margin and vice versa). Second, on average, positive changes in farm and retail prices seem to be larger than negative changes, although only very slightly. Finally, retail prices are fairly sticky in spite of changes in market conditions, indicating some kind of asymmetric price transmission. However, these issues have to be further explored with appropriate methodological tools, which will be the aim of the following sections.

Asymmetries in the Spanish lamb meat market may arise due to the retailers' use of market power to transmit input price increases faster than input price decreases. Retailers try to maintain their 'normal' profit margin when price rise, but they try to capture the larger margins that arise, at least temporarily, when farmer prices fall. In both cases, the situation lasts only as long as consumer search costs are present. When costly search is completed, prices tend towards competitive levels and profits go down. In Spain, the lamb marketing chain is highly concentrated downstream while farms generally lack the capacity to negotiate prices. In the past fifteen years, Europe (and, particularly, Spain) has witnessed a sharp 
increase in the trend of mergers and acquisitions within the food retail sector. In 2002, the largest retail company in Spain accounted for 31 per cent of market share (London Economics, 2004). The leader had a higher market share than the combined market shares of the second and third largest retailers, which only accounted for 25 per cent.

\section{(Insert Figure 3)}

Accountancy rules and inventory management strategies may also be responsible for the sluggish adjustment of retail prices to changes in farm prices variables. In the case of meat products, Spanish retailers have usually adopted the First-In First-Out (FIFO) criterion to valuing inventories (Ulloa, 2005). As a consequence, it is expected that retailers do not adjust prices immediately when costs change, but wait until stocks bought at pre-change prices are depleted, thus potentially reducing the speed of the price adjustment process.

Finally, menu costs are not very important for explaining price transmission asymmetries along the lamb marketing chain. Azzam (1999) showed that when retailers incur re-pricing costs, changes in farm prices do not trigger retail price modifications. However, lamb meat is a perishable product mainly sold in big pieces that the butcher has to cut. No labels, apart from specific quality labels, are present. Stock levels are usually very low as retailers buy quite frequently. Thus, re-pricing costs are irrelevant, as retailers only have to change the price. In the case of specific cuts already packed, the stock disappears in less than a week.

\section{$3 \quad$ Modelling non-linear adjustments}

Asymmetries in vertical price transmission were initially investigated using variations of a model first developed by Wolffram (1971) and later modified by Houck (1977) ${ }^{7}$. The response of the retail price (RP) to a shock in the farm price (FP) was calculated by estimating the following equation:

$$
\Delta R P_{t}=\gamma_{0}+\gamma_{1}^{+} D_{t}^{+} \Delta F P_{t}+\gamma_{1}^{-} D_{t}^{-} \Delta F P_{t}+u_{t}
$$

\footnotetext{
${ }^{7}$ However, empirical work to investigate asymmetries in price transmission started earlier and was based on the estimation of irreversible supply functions. Meyer and von Cramon-Taubadel (2004) and Frey and Manera (2007) provide exhaustive reviews of methodological approaches to investigating price transmission using price data.
} 
where RP and FP are the retail price and farm prices, respectively, $\Delta$ indicates first differences, $D_{t}^{+}$and $D_{t}^{-}$are dummy variables that take the value 1 if $F P_{t} \geq F P_{t-1}$ and $F P_{t}<F P_{t-1}$, respectively, and 0 , otherwise, $\gamma_{0}, \gamma^{+}$and $\gamma^{-}$are parameters to estimate, and $u_{t}$ is the disturbance term. From (1), the null hypothesis of symmetric price transmission $\left(\mathrm{H}_{0}\right.$ : $\left.\gamma^{+}=\gamma^{-}\right)$can be tested against the alternative of asymmetry $\left(\mathrm{H}_{\mathrm{a}}: \gamma^{+} \neq \gamma^{-}\right)$.

Equation (1) suffers from three main limitations. First, the response of retail prices to changes in farm prices is generally not instantaneous but instead is distributed over time. Second, it assumes that causality goes from farm to retail prices only (i.e. a cost-push price transmission mechanism). Third, the model does not adequately consider the time series properties of data. To solve the first limitation, Ward (1982) extended equation (1) by including lags of the exogenous variables:

$$
\left.\Delta R P_{t}=\gamma_{0}+\sum_{j=1}^{M}\left(\gamma_{j}^{+} D_{t}^{+} \Delta F P_{t-j+1}\right)+\sum_{j=1}^{N} \gamma_{j}^{-} D_{t}^{-} \Delta F P_{t-j+1}\right)+u_{t}
$$

$\mathrm{M}$ and $\mathrm{N}$ in equation (2) can differ, as there is not a priori reason to expect identical laglengths for the increasing and decreasing phases of prices transmission ${ }^{8}$.

Equation (2) would be adequate to test for asymmetries in price transmission provided price series were stationary. However, price levels often exhibit non-stationary covariance, which may lead to autocorrelation problems in the asymmetric price response function. Moreover, if the price series are cointegrated, the estimated parameters in (2) would be biased as a result of the misspecification of the long-run relationships between prices. Von Cramon-Taubadel (1998) proposed an alternative specification of the Wolffram-Houck-Ward model based on the error correction representation. His method consists of estimating the following long-run relationship between the retail and the farm prices:

$$
R P_{t}=\beta_{0}+\beta_{1} F P_{t}+u_{t}
$$

If tests prove that equation (3) is not a spurious regression (i.e. prices are cointegrated) the lagged residuals from the estimated equation $\left(\hat{u}_{t-1}\right)$ are divided into positive $\left(\hat{u}_{t-1}^{+}\right)$and

\footnotetext{
${ }^{8}$ See, for instance, Kinnucan and Forker (1987).
} 
negative components $\left(\hat{u}_{t-1}^{-}\right)$(i.e. positive and negative deviations from the long-run equilibrium) and the following error correction model (ECM) is estimated:

$$
\Delta R P_{t}=\gamma_{0}+\sum_{j=1}^{M}\left(\gamma_{j}^{+} D_{t}^{+} \Delta F P_{t-j+1}\right)+\sum_{j=1}^{N}\left(\gamma_{j}^{-} D_{t}^{-} \Delta F P_{t-j+1}\right)+\psi^{+} \hat{u}_{t-1}^{+}+\psi^{-} \hat{u}_{t-1}^{-}+\varepsilon_{t}
$$

Balke et al. (1998) also use an ECM to test for asymmetric adjustment. As parameters $\psi^{+}$ and $\psi^{-}$in (4) are constant, the model assumes that a constant proportion of any deviation from the long-run equilibrium is corrected, regardless of the size of this deviation (i.e. the model is based on linear error correction) (Meyer and von Cramon-Taubadel, 2004). The presence of fixed costs of adjustment along the food chain may generate non-linear reactions; that is to say, price adjustments may be different depending on both the magnitude and the sign of the initial shock. Thus, it is not unrealistic to suppose that only when the initial shock surpasses a critical threshold do economic agents react to it.

Different methodological alternatives have been proposed in the literature to make cointegration and non-linear adjustments compatible. Chavas and Metha (2004) developed an augmented error correction model allowing the dynamic price adjustment to differ among regimes defined by the corresponding threshold parameters. However, under this approach, threshold parameters are exogenously determined. Partly for this reason, recent contributions have explored methodological alternatives that allow threshold parameters to be endogenously determined. Among these, the most commonly used are the Markov switching vector error correction model (MSVECM) (Krolzig and Toro, 2001), the threshold autoregressive model (TAR) (Balke and Fomby, 1997), and the threshold vector error correction model (TVECM) (Lo and Zivot, 2001). While the TAR model is a univariate procedure, the TVECM is multivariate. As such a procedure utilises the full structure of the model, it should have higher power, providing the model is true, than univariate procedures. Moreover, the TAR model assumes that only the adjustments to the equilibrium change with regimes, while the autoregressive parameters of the model remain constant. The MSVECM does not take the time series nature of price data into account, which may lead to a loss of efficiency, and greatly reduces the insights into the dynamics of price response that can be derived. Taking into account these considerations, we opted to use the TVECM to analyse the price transmission along the Spanish lamb marketing chain (providing that price series are non-stationary and cointegrated and that price adjustments are non-linear). 
More precisely, the approach followed in this paper is to start the analysis by considering a general three-regime threshold vector error correction model $\left(\mathrm{TVECM}_{3}\right)$. In a second step, several tests are considered to check if the estimated model is preferable over a two-regime $\mathrm{TVECM}_{2}$ or a linear VECM. Finally, short-run dynamics are analysed. In the following two sub-sections we outline the main characteristics of the procedure used in this study.

\subsection{Threshold cointegration}

Let $\mathrm{P}_{\mathrm{t}}=\left(\mathrm{RP}_{\mathrm{t}}, \mathrm{FP}_{\mathrm{t}}\right)^{\prime}$ be a vector containing the logged prices of a good at retail and farm levels. If the two prices are I(1) time series cointegrated with cointegrating vector $\beta^{\prime}=\left(1,-\beta_{2}\right)$, the linear VECM representation of order $\mathrm{k}$ of $\mathrm{P}_{\mathrm{t}}$ can be written as:

$$
\Delta P_{t}=\alpha\left[\omega_{t-1}(\beta)\right]+\sum_{i=1}^{k-1} \Gamma_{i} \Delta P_{t-i}+u_{t}
$$

where $\omega_{t-1}(\beta)=\beta^{\prime} P_{t-1}$ is the cointegrating vector evaluated at the generic value $\beta=\left(1,-\beta_{2}\right)^{\prime} ; \Gamma_{i}$, $i=1,2 \ldots$ are $(2 \times 2)$ matrices of short-run parameters; $\alpha$ is a $(2 \times 1)$ vector; and $\underline{\underline{u}}_{\mathrm{t}}$ is a vector of disturbance terms that are assumed to be independently and identically Gaussian distributed, with covariance matrix $\Sigma$, which is assumed to be positive definite. $\beta$ is the cointegrating vector which is defines the long-run equilibrium relationship between the two prices in $P_{t}$, while $\alpha$ gives the weights of the deviations from the cointegration relationship in the VECM equations.

The three-regime threshold vector error correction model $\left(\mathrm{TVECM}_{3}\right)$, can be written as:

$$
\Delta P_{t}=\left\{\begin{array}{lll}
\alpha \omega_{t-1}(\beta)+\sum_{i=1}^{k-1} \Gamma_{i}^{1} \Delta P_{t-i}+u_{t}^{1}, & \text { if } & \omega_{t-1}(\beta)<\lambda^{1} \\
\alpha^{2} \omega_{t-1}(\beta)+\sum_{i=1}^{k-1} \Gamma_{i}^{2} \Delta P_{t-i}+u_{t}^{2}, & \text { if } & \lambda^{1} \leq \omega_{t-1}(\beta) \leq \lambda^{2} \\
\alpha^{3} \omega_{t-1}(\beta)+\sum_{i=1}^{k-1} \Gamma_{i}^{3} \Delta P_{t-i}+u_{t}^{3}, & \text { if } & \omega_{t-1}(\beta)>\lambda^{2}
\end{array}\right.
$$

where $\omega_{t-1}(\beta)$ is the threshold variable representing the residual of the equilibrium relationship (i.e. a deviation from equilibrium), and $\lambda=\left(\lambda^{1}, \lambda^{2}\right)$ are the threshold parameters that delineate the different regimes. As can be observed, the $\mathrm{TVECM}_{3}$ in (6) specifies that the 
adjustment towards the long-run equilibrium relationship is regime-specific. This model says that the dynamic adjustment of $P_{\mathrm{t}}$ depends on the magnitude of $\omega_{t-1}(\beta)$.

In general, the threshold parameters $\left(\lambda^{1}, \lambda^{2}\right)$ are unknown and need to be estimated along with the remaining parameters of the model. Lo and Zivot (2001) proposed a strategy that combines Hansen's (1999) approach to estimate two- and three-regime univariate TAR models and Tsay's (1998) procedure for estimating a multivariate TVECM. This strategy consists of the following steps.

In the first step, two-dimensional grid searches are carried out to estimate the threshold parameters $\left(\lambda^{1}, \lambda^{2}\right)$. Letting $T_{i}$ be the number of observations in regime $I$ and $T$ the total number of observations in the sample, the threshold parameters are constrained such that $T_{i} / T \geq \pi_{0}$, with $\pi_{0}$ typically set to 0.1 . Conditional on $\lambda=\left(\lambda^{1}, \lambda^{2}\right)$, the $\operatorname{TVECM}_{3}$ in (6) is linear in the remaining parameters and may be estimated by iterative multivariate least squares minimising:

$S_{3}\left(\lambda^{1}, \lambda^{2}\right)=\ln \left|\hat{\Sigma}_{3}\left(\lambda^{1}, \lambda^{2}\right)\right|$

where $\hat{\Sigma}_{3}\left(\lambda^{1}, \lambda^{2}\right)$ is the estimated covariance matrix of (6), conditional on $\lambda^{1}$ and $\lambda^{2}$.

The optimal threshold parameters can be estimated using the following optimisation program $^{9}$ :

$\left(\hat{\lambda}^{1}, \hat{\lambda}^{2}\right)=\arg \min \left(S_{3}\left(\lambda^{1}, \lambda^{2}\right)\right)$

In the second step, conditional on the estimated threshold parameters, the remaining parameters can be estimated by standard procedures and the residual covariance matrix is given by $\hat{\Sigma}_{3}(\hat{\lambda})=\hat{\Sigma}_{3}\left(\hat{\lambda}^{1}, \hat{\lambda}^{2}\right)$. Tsay (1998) showed that the conditional least squares estimator of the $\mathrm{TVECM}_{3}$ is strongly consistent as the sample size increases, and that the parameters of the $\alpha^{i}$ and $\Gamma_{j}^{i}(j=1, \ldots, k-1)$ matrices are asymptotically normally distributed.

${ }^{9}$ The grid research minimises the log determinant of the residual covariance matrix of the $\mathrm{TVECM}_{3}$, which is analogous to maximising a standard LR test statistic. 
A special case of the TVECM 3 given in (6) occurs if price changes in the second regime (the middle one) are smaller than the transaction costs. In this case, prices will not adjust in this regime, implying that prices are not cointegrated, that is, $\alpha^{2}=0$. The resulting model is the socalled Band-TVECM. In this case, if $\omega_{t-1}(\beta)$ is within the band, then prices are not cointegrated and $P_{t}$ follows a $\operatorname{VAR}(k)$ without a drift. However, in the outer bands economic forces make prices move together, implying cointegration with different adjustment coefficients.

As mentioned above, once the $\mathrm{TVECM}_{3}$ has been estimated, several tests can be used in the literature to check whether the dynamic behaviour and the adjustment towards the long-run equilibrium relationship is linear or exhibits threshold non-linearity (Hansen, 1999 and Tsay, 1998). Lo and Zivot (2001) suggested that Hansen's method for testing linearity in univariate TAR models, based on nested hypothesis tests, can be easily extended to test for linearity in multivariate TVECMs. So, they proposed the sup-LR statistic:

$$
L R_{13}=T\left(\ln |\hat{\Sigma}|-\ln \left|\hat{\Sigma}_{3}(\hat{\lambda})\right|\right)
$$

where $\hat{\Sigma}$ and $\hat{\Sigma}_{3}(\hat{\lambda})$ are the residual covariance matrices of the VECM (5) and the threeregime $\mathrm{TVECM}_{3}(6)$, respectively.

The statistic to test this hypothesis suffers from the so-called problem of unidentified nuisance parameters under the null hypothesis. In other words, the non-linear model contains certain parameters that are not restricted under the null hypothesis and are not present in the linear model given by (5). Consequently, conventional statistical theory cannot be applied to obtain the asymptotic distribution of the statistics (Hansen, 1999 and Hansen and Seo, 2002). Given that the test statistic has a non-standard distribution, Hansen and Seo (2002) suggested using the fixed regressor bootstrap or, alternatively, a parametric residual bootstrap algorithm to compute the $\mathrm{p}$-value for the linearity tests ${ }^{10}$.

\footnotetext{
${ }^{10}$ In both cases, we ran 1000 simulations to estimate the non-linear model replacing either the dependent variables $\left(P_{t}\right)$ (fixed regressor bootstrap algorithm) or both the dependent and righthand regressors (parametric residual bootstrap algorithm) by iid $\mathrm{N}(0,1)$ draws. The proportion of simulations under the null for which the simulated LR exceeds the observed LR statistic gives the asymptotic $p$-value of the sup-LR test.
} 
Once the presence of threshold effects is confirmed, the second question to answer is what kind of threshold model is more appropriate for the data (number of regimes, usually two versus three). Lo and Zivot (2001) suggested using the following Likelihood Ratio (LR) statistic to test the null of a $\mathrm{TVECM}_{2}$ (two-regime model) against the alternative of a $\mathrm{TVECM}_{3}$ (three-regime model):

$$
L R 2,3=T\left(\ln \left[\hat{\Sigma}_{2}(\hat{\lambda})\right\rfloor-\ln \left[\hat{\Sigma}_{3}(\hat{\lambda}) \mid\right)\right.
$$

where $\hat{\Sigma}_{2}(\hat{\lambda})$ and $\hat{\Sigma}_{3}(\hat{\lambda})$ are the estimated residual covariance matrices from the unrestricted two-regime $\mathrm{TVECM}_{2}$ and three-regime $\mathrm{TVECM}_{3}$, respectively. The asymptotic distributions of $\mathrm{LR}_{2,3}$ are non-standard, and bootstrap methods can be used to compute approximate $\mathrm{p}$ values.

As a final step, if the $\mathrm{TVECM}_{3}$ is chosen, it is possible to test whether such a model could be formulated as a Band-TVECM $\left(\alpha^{2}=0\right)$. Since the estimated threshold parameters from the $\mathrm{TVECM}_{3}$ are superconsistent, as mentioned previously, then a Wald test can be used, which follows an asymptotic $\chi^{2}$ distribution.

\subsection{Short-run dynamics}

In TVECMs the short-run dynamic behaviour of the variables is analysed by computing the impulse response functions (IRF). This can be particularly suitable for studying the time path response of variables to unexpected shocks at time t. However, given that the non-linear time series model does not have a Wold representation, computing the IRF for this type of model is not an easy task. In addition, as discussed in Koop et al. (1996), complications arise because in non-linear models i) the effect of a shock depends on the history of the time series up to the point where the shock occurs, and ii) the effect of a shock depends on the sign and the size of the shock. As a consequence, in non-linear models impulse response functions depend on the combined magnitude of the history, $P_{t-1}=\varphi_{t-1}$, and the magnitude of shock, $\delta$.

Generalised impulse response functions (GIRF), introduced by Koop et al. (1996) and Potter (1995), capture the asymmetric response of the variables to one standard deviation of both positive and negative shocks. The Non-linear Impulse Response Functions (NIRF) are defined in a similar way as traditional GIRF, except for replacing the standard linear predictor by a conditional expectation. Hence, the NIRF for a specific shock $u_{t}=\delta$ and history $\mathrm{P}_{\mathrm{t}-1}=\varphi_{\mathrm{t}}$ 1 (the history of the system) is defined as: 


$$
\begin{aligned}
\operatorname{NIRF}\left(n, \delta, \varphi_{t-1}\right) & =E\left[P_{t+n} \mid u_{t}=\delta, u_{t+1}=\ldots=u_{t+n}=0, \varphi_{t-1}\right] \\
& -E\left[P_{t+n} \mid u_{t}=0, u_{t+1}=\ldots=u_{t+n}=0, \varphi_{t-1}\right] \text { for } n=0,1, \ldots N
\end{aligned}
$$

Taking this definition into account, it is clear that the NIRF is a function of $\delta \in u_{\mathrm{t}}$ and $\varphi_{t-1} \in \Omega_{t-1}$ ( $\Omega_{t-1}$ is the history or information set at t-1 used to forecast future values of $P_{t}$ ). Given that $\delta$ and $\varphi_{t-1}$ are realisations of the random variables $\Omega_{t-1}$ and $u_{t}$, Koop et al. (1996) stressed that NIRF themselves are realisations of random variables given by:

$$
\operatorname{NIRF}\left(n, u_{t}, \Omega_{t-1}\right)=E\left[P_{t+n} \mid u_{t}, \Omega_{t-1}\right]-E\left[P_{t+n} \mid \Omega_{t-1}\right]
$$

From (12), there are various alternative ways of calculating the NIRF, depending on the research objectives. For instance, in this study we wanted to assess the responses of farm (retail) prices to shocks in retail (farm) prices under different price evolution regimes and for different sizes and signs of the initial shock. In particular, the NIRF can be used to evaluate the degree of asymmetric responses over time. Potter (1995) defined a measure for assessing the asymmetric response to a particular shock, given a particular history $\varphi_{\mathrm{t}-1}$, as the sum of NIRF for this particular shock and the NIRF for the shock of the same magnitude but with the opposite sign, that is:

$$
\operatorname{ASY}\left(n, u_{t}, \varphi_{t-1}\right)=\operatorname{NIRF}\left(n,+\delta_{i}, \varphi_{t-1}\right)+\operatorname{NIRF}\left(n,-\delta_{i}, \varphi_{t-1}\right)
$$

\section{$4 \quad$ Data and preliminary analysis}

Weekly data of farmer prices (FP) and retail (RP) prices $^{11}$ for period 1996-2002 were used. All variables were expressed in natural logarithms. Cointegration analyses between prices it commonly use logarithms because otherwise, with trending data, the relative error declines through time (Banerjee et al., 1993). Furthermore, from a statistical point of view, Hamilton (1994) pointed out that the logarithmic transformation mitigates fluctuations of individual

\footnotetext{
11 Price series are expressed in nominal terms. Although cointegration is more likely to be found, by removing inflationary trends one would assume that the two prices are affected in the same manner by inflation and return to a long-run equilibrium in the same amount of time. Starleaf et al. (1985) and Larue (1991) showed that this assumption is incorrect, at least with US data. Moreover, as a result of low inflation in the period covered, there is no necessity to deflate prices series (Alderman, 1993).
} 
series increasing the likelihood of stationarity after first differencing. From an economic point of view, this transformation allows us to interpret results in percentage change terms ${ }^{12}$.

Seasonality was investigated by implementing seasonal unit root tests for weekly data following the procedure suggested by Cáceres $(1996)^{13}$. The results clearly suggest that seasonality is deterministic for the two price series. Accordingly, the systematic component of seasonality was captured, to be parsimonious, using a Fourier-type series expansion ${ }^{14}$, and the price series were seasonally adjusted.

Unit root tests were conducted on the univariate time series. As such tests have limited power in small samples, two alternative unit root tests (Elliot et al., 1996; ; Ng and Perron, 2001) as well as the stationary test from Kwiatkowski et al. (1992) (KPSS) were applied. All results are consistent with the presence of a unit root without drift in the two price series, satisfying the first necessary condition for cointegration analyses ${ }^{15}$.

\section{$5 \quad$ Results}

Empirical specification of TVECM involves the following steps: i) under the assumption of price non-stationarity, testing for cointegration and estimating the cointegrating relationships;

${ }^{12}$ That is, prices are related in terms of percentage variations instead of absolute changes, which seems appropriate for marketing margins set in percentage terms, as is the case in the Spanish lamb marketing chain (Ulloa, 2005). Note also that absolute changes were not stationary while percentage variations oscillated around a stable mean (Figure 2).

${ }^{13}$ The procedure is similar to that used by Franses (1991), for monthly data, and is based on the decomposition of the polynomial $\left(1-L^{52}\right)$. Results are available from the authors upon request.

${ }^{14}$ Following Doran and Quilkey (1972) and Goodwin et al. (2002), the seasonal component $\left(S_{t}\right)$ of each series has been captureed by estimating the following regression:

$$
S_{t}=\sum_{i=1}^{p} \lambda_{i} \cos \left(2 \pi s w_{t} / 52\right)+\sum_{i=1}^{p} \gamma_{i} \sin \left(2 \pi s w_{t} / 52\right)
$$

where $p$ is the number of cycles within the year and $s w_{\mathrm{t}}$ indicates the order of the week within the year. Here, $p$ has been set to 2 , as with $p=3$, most of the estimated coefficients were insignificant.

${ }^{17}$ Results are available upon request. 
ii) if cointegration is found, determining whether the dynamics of the data can be described by threshold-type non-linearities; iii) estimating the bivariate threshold error correction model (TVECM) if linearity is rejected, and iv) calculating non-linear Generalised Impulse Response functions in order to analyse the response of each price to unanticipated positive and negative shocks. Each of these steps is addressed in turn in this section.

\subsection{Cointegration analysis}

In this section we address the first step for specifying a TVECM. Cointegration is tested using the likelihood ratio test introduced by Johansen $(1988)^{16}$. A four-lag VAR system with a restricted constant was specified as the underlying model for carrying out cointegration rank tests. The optimum lag was selected on the basis of the Akaike Information Criterion (AIC) and the Likelihood Ratio test proposed (Tiao and Box, 1981). Moreover, according to the results from the unit root tests, the hypothesis that $\mathrm{E}\left[\Delta P_{t}\right]=0$ cannot be rejected for both prices, indicating that there is no evidence of a linear trend in the data. In any case, following Johansen (1995) several tests were conducted to select empirically the deterministic component introduced in the model. Results clearly indicate that a model with a restricted constant is statistically preferred. ${ }^{17}$ Misspecification tests for autocorrelation (Doornik and Hendry, 1997) indicated that the model specified with four lags and a restricted constant was quite satisfactory.

Results from these tests indicated that, at the 5 per cent level of significance, the null hypothesis of one cointegrating vector could not be rejected (the trace statistic was 57.35, which is well above the critical value, 20.12). Given that the cointegrating rank is one, we tested whether the elasticity of price transmission between farm and retail prices is equal to unity in the long run. This hypothesis states that the cointegrating vector, $\beta$, should satisfy the long-run condition $(1,-1)$. All the restriction tests on the cointegrating vector are

\footnotetext{
${ }^{16}$ Escribano and Mira (1996) showed that the cointegrating vector can still be estimated superconsistently in the presence of neglected non-linearity in the adjustment process.

${ }^{17}$ The null hypothesis of a restricted (unrestricted) constant against the alternative hypothesis of an unrestricted constant and a restricted trend was accepted at the 5 per cent significance level, as was the null of a restricted constant against the alternative of an unrestricted constant.
} 
asymptotically $\chi^{2}(v)$ distributed, where $v$ is the number of imposed restrictions ${ }^{18}$. The Likelihood Ratio (LR) statistic (1.19) did not reject the restriction at the 5 per cent significance level. In the long run, any change in the farm price generates a change of the same size at the retail level, keeping marketing margins constant over time, as shown in Figure $2 b^{19}$. The restricted cointegrating vector is given by:

$\ln R P-\ln F P=0.635$

The constant term in (14) represents the price spread at the retail level. Taking into account that all prices are expressed in logarithms, equation (14) represents percentage spread models with a mark-up of $\left(e^{\alpha}-1\right)(\alpha$ being the constant). Hence, the retail marketing margin can be expressed as follows:

Retail margin $=\left(e^{\alpha}-1\right) \times F P \times 100=0.89 F P \times 100$ per cent.

\subsection{Threshold cointegration}

Once the presence of a long-run equilibrium relationship between the two prices has been detected, the next question is whether non-linearities exist in the adjustment process. This question was analysed using the procedure described in Section 3. We started by testing nonlinearity since, if the null of linearity is rejected, the number of regimes in the TVECM has to be determined considering the estimated cointegrating vector, given in (14), as the threshold variable $\left(\omega_{t-1}\right)^{20}$. The results of testing LR linearity against the alternative of a multivariate TVECM $_{3}\left(\mathrm{LR}_{1,3}\right)$ are shown in Table 1 and indicate that the null is rejected, at the 5 per cent level, in favour of the threshold model.

(Insert Table 1)

\footnotetext{
${ }^{18}$ For further details, see Johansen (1995).

${ }^{19}$ Although this result would imply perfectly competitive behaviour in the Spanish lamb chain, we have to interpret it with caution as we are only using price data. In fact, McCorriston et al. (2001) and Lloyd et al. (2006) showed that this result could be also compatible with the presence of market power and increasing returns to scale.

${ }^{20}$ The residuals obtained from equation (14) can be interpreted as deviations from a long-term equilibrium.
} 
Next we tested which threshold model is more appropriate for characterising the non-linear dynamic adjustments of prices using the $\mathrm{LR}_{2,3}$ statistic given in expression (10). Table 1 shows that the LR statistic rejects the null of a $\mathrm{TVECM}_{2}$ against the alternative of a threeregime $\mathrm{TVECM}_{3}$, suggesting that price transmission along the Spanish lamb marketing chain can be characterised by a three-regime threshold process. At the bottom of Table 1, the estimated threshold parameters from the $\operatorname{TVECM}_{3}$ are shown $(\hat{\lambda}=(-0.0679,-0.0065))$. In other words, and taking (14) into account, the TVECM splits the price adjustment process depending on whether the retail marketing margin lies below 76 per cent, above 87 per cent or between 76 per cent and 87 per cent. Figure 4 reports the evolution of farm and retail prices under the three regimes according to the corresponding threshold parameters. At the first regime the marketing margin is too low leading to a negative error-correction term, which causes the retail price to increase and the farm price to decrease. This is indeed what we observe in Figure 4 as at regime 1 the retail prices are in an increasing phase while the farm prices seem to reach their top and are ultimately going to decrease. In the third regime the retail margin is too high leading to a positive error-correction term making the retail price to decrease and the farm price to rise. Thus, as observed in Figure 4, at the regime 3 the retail price is in a decreasing phase while the farm price is at the bottom level and is ultimately going to increase.

\section{(Insert Figure 4)}

The estimated $\mathrm{TVECM}_{3}$ coefficients are shown in Table 2 along with the results from the misspecification tests. The results from the diagnostic tests suggest that the estimated model is adequate as there is no evidence of remaining residual autocorrelation, the ARCH tests fail to reject the null of homoscedasticity ${ }^{21}$ and, normality cannot be rejected. Moreover, the estimated parameters in the outer regimes (except $\alpha_{2}^{1}$ ) are significant at the 5 per cent level, and have the expected sign. However, in the middle regime (regime 2), both adjustment coefficients are not significant, indicating that adjustment only takes place beyond the edge of the threshold band. Within the band, the two prices move closer to each other but without following any specific pattern.

${ }^{21}$ Only in the case of the retail price the $\operatorname{ARCH}(52)$ statistic is borderline, with $p$-value = 0.0497 . 


\section{(Insert Table 2)}

Considering this result, the TVECM 3 could be re-specified as a Band-TVECM as defined in Section 3. A Wald test accepted the hypothesis that the adjustment coefficients in the middle regime are jointly zero. Consequently, it can be concluded that the Band-TVECM is more appropriate than the unrestricted TVECM for representing the asymmetric adjustments of lamb prices along the market chain.

To further illustrate the extent of asymmetric effects in our model, we calculated the half-life, which is the number of periods required to reduce one-half of a deviation from the long-run equilibrium. In case of a VAR(1), the half-life for the $\mathrm{j}^{\text {th }}$ regime is obtained as follows:

$$
n^{j}=\ln (0.5) / \ln \left(\rho^{j}\right)
$$

where $\rho^{j}=1+\beta^{\prime} \alpha^{j}=1+\left[\begin{array}{ll}1 & -\beta_{2}\end{array}\right]\left[\begin{array}{c}\alpha_{1}^{j} \\ \alpha_{2}^{j}\end{array}\right]=1+\alpha_{1}^{j}-\beta_{2} \alpha_{2}^{j}$

However, for higher order VARs the calculation of the half-life is not straightforward ${ }^{22}$. In this paper we calculate them from the Persistence Profiles (PP) developed by Pesaran and Shin (1996). The Persistence Profiles provide information on the speed with which long-run relations, once shocked, will return to their equilibrium (i.e. the speed with which the effects of system-wide shocks on the cointegration relation disappears). The Persistence Profiles are calculated from the Impulse Response Functions (Section 3.2). Given than in non-linear models impulse response functions depend on both the history $P_{t-1}=\varphi_{t-1}$ and the magnitude of the shock $\delta$, persistence profiles are also non-linear ${ }^{23}$ :

$P P_{\omega_{t}}\left(n, \varepsilon_{t}, \Omega_{t-1}\right)=\beta^{\prime} N I R F \beta$

Since the Persistence Profiles start at unity and falls to zero as $(T \rightarrow \propto)$, we can compute the half-life measure as the time horizon over which the Persistence Profile falls to 0.5. This

\footnotetext{
${ }^{22}$ We thank an anonymous referee for pointing this out.

23 In linear models the Persistence Profile of the cointegrating relation is given by $P P_{\omega_{t}}(n)=\beta^{\prime} H_{P}(n) \beta$, where $H_{P}(n)$ is the system-wide impulse responses of variables $\left(\mathrm{P}_{\mathrm{t}}\right)$ in the model.
} 
provides a simple measure of the speed of adjustment with which the stationary price relationship returns to its equilibrium.

We calculated the Persistence Profiles for each regime (regimes 1 and 3) for system-wide shocks $\delta= \pm 1$. Figure 5 shows that the speed of adjustment is faster in regime 3 than in regime 1. In fact, the computed half-life associated with a positive (negative) shock starting at the upper regime is 4 weeks ( 7 weeks), which is significantly shorter than the half-life associated to positive (negative) shocks starting at the lower regime [18 weeks (12 weeks)]. A second interesting result is that, in the lower regime (i.e. when the marketing margin is below the lower threshold level) the reversion is faster when the initial shock is negative, while the opposite takes place in the upper regime (i.e. when the marketing margin is above the upper threshold level). That is, the speed of adjustment is faster when the sign of the initial shock is opposite to the marketing margin level.

\section{(Insert Figure 5)}

In any case, the key feature in threshold models is the significance of the estimated coefficients of the $\alpha^{j}$ matrices associated with the cointegrating vector $\omega_{t-1}(\beta)$. These coefficients can be useful to analyse which prices "equilibrium adjust", and which do not. The estimated parameters of the Band-TVECM are:

$$
\left(\begin{array}{l}
\alpha_{1}^{1} \\
\alpha_{2}^{1}
\end{array}\right)=\left(\begin{array}{c}
-0.062 \\
(0.025) \\
0.031 \\
(0.015)
\end{array}\right) \quad \text { and } \quad\left(\begin{array}{l}
\alpha_{1}^{3} \\
\alpha_{2}^{3}
\end{array}\right)=\left(\begin{array}{c}
-0.058 \\
(0.022) \\
0.108 \\
(0.043)
\end{array}\right)
$$

where values in parentheses represent standard errors.

The first point to note is that all adjustment coefficients corresponding to both the lower and the upper regimes are statically significant, which implies that both positive and negative deviations from the long-run price relationship revert to their original level. However, one main difference is observed in relation to the speed of adjustment. In the case of retail prices, in absolute values, the adjustment coefficients corresponding to the lower and the upper regimes (-0.062 and -0.058 , respectively) are not statistically different ${ }^{24}$. This result is consistent with Figure 3 which shows that in the Spanish lamb chain retail price changes were

${ }^{24}$ The test statistic is 0.11 , which is well under the critical value at the $5 \%$ level of significance (3.84). 
relatively small either when marketing margins increased or decreased. However, in the case of farm prices the adjustment coefficient corresponding to the upper regime is larger than that corresponding to the lower regime.

Given the fact that the adjustment parameters of the retail price are not significantly different between regimes 1 and 3 while the adjustment parameter of the farm price in regime 1 (regime 3) is smaller (higher) than the absolute value of the adjustment parameter of the retail price, if retail prices are increasing and farm prices are at their top and are ultimately going to decrease, then the too low retail margin in regime 1 will be squeezed while being adjusted upwards to equilibrium in comparison with the symmetric case in which the adjustment parameter of the farm price is not lower than the absolute value of the adjustment parameter of the retail price. Hence, a higher adjustment parameter of the farm price will lead to a faster speed of adjustment in case of a negative error-correction term. However, if the retail margin is too high as in regime 3, then it will also be squeezed while being adjusted downwards when compared with the situation in which the adjustment parameter of the farm price is not larger than the absolute value of the adjustment parameter of the retail price, because the farm price is increasing faster than the retail price is decreasing. But now, in regime 3, we see that with a positive error-correction term (in contrast to the negative error-correction term in regime 1) the speed of adjustment is faster than in regime 1. Consequently, the adjustment parameters show that excessively high retail margins (regime 3 ) last much shorter than retail margins that are too low (regime 1$)^{25}$. These results are consistent with what we have observed previously in the Persistence Profiles (Figure 5) where the estimated half-life in the upper regime is substantially lower (4-7 weeks) than the one obtained for the third regime (12-18 weeks). However, not only the length but also the magnitude of responses matters. This is precisely what we are going to analyse in the following section.

\subsection{Short-run dynamics}

Short-run dynamics were analysed by computing the IRFs, which show the response of each price in the system to a shock in any other price. Non-linear IRFs (NIRF) were calculated for regimes 1 and 3. In a context of non-linear models, NIRFs are a very useful tool as they allow

\footnotetext{
${ }^{25}$ We thank to an anonymous referee for helpful suggestions to interpreting the adjustment parameters
} 
us to measure in a non-linear framework the responses to positive and negative shocks and the significance of asymmetric effects over time. Moreover, in which regime the shock occurs is relevant, as the response is regime-specific.

In order to analyse the asymmetric behaviour of price adjustments, the NIRFs were computed for $\delta= \pm 1$ and \pm 2 and for history-specific regimes so that the long-run equilibrium relationship $\left[\omega_{t-1}(\beta)=\beta^{\prime} P_{t-1}\right]$ is above or below the upper and lower threshold values. In each regime, the NIRF for each forecasting horizon is the average across all possible $\mathrm{N}_{\mathrm{i}}$ histories (with $\mathrm{N}_{\mathrm{i}}$ being the number of observations in the ith regime) (Kapetanios, 2003). For each response, we computed the corresponding 95 per cent confidence intervals using bootstrapping techniques based on 5,000 replications ${ }^{26}$. The main results are shown in Figures 6 and $7^{27}$. Significant responses are marked with a square symbol (closed for retail prices and open for farm prices).

Figure 6 shows, in the upper part, the responses of both prices to a shock in farm prices in both regimes while, in the lower, Potter's (1995) measure for assessing asymmetric responses is provided (see equation (13)). Under the first regime (retail margin is too low), a positive shock in the farm price squeezes the marketing margin for the first three weeks after the shock, as the retail price response is less than half that of the farm price ${ }^{28}$. To restore equilibrium, the farm price should ultimately decrease and the retail price should rise (this take place after 10 weeks). This behaviour can be explained by the perishability of the

${ }^{26}$ All the analyses have been carried out in GAUSS. We are grateful to Dr. Dick van Dijk for providing valuable information on how to tackle this cumbersome task.

${ }^{27}$ In the upper part, and to reduce complexity, Figures 6 and 7 only show impulse responses for $\delta= \pm 1$, while in the lower part, the Potter's measure is provided adding the responses for $\delta= \pm 1$ and \pm 2 . Impulse responses for $\delta= \pm 2$ follow the same pattern as those shown in the Figures. Results are available from authors upon request.

28 This result is also consistent with what we expected, although very roughly as we only considered contemporaneous but not lagged changes in Section 2 (Figure 3). 
product. In a phase of rising prices, retailers may prefer to accept a reduction in their marketing margin to avoid the risk of being left with a spoiled product ${ }^{29}$.

\section{(Insert Figure 6)}

However, these margin losses are compensated in the case of excess supply shocks. As can be observed, a negative shock in farm prices stretches the retail margin significantly. Then if the retail margin becomes so high that regime 3 applies, then ultimately the farm price is going to increase and the retail price is going to decrease. For both farm and retail prices, the reaction to positive and negative shocks in farm price is positive-asymmetric (lower left panel of Figure 6): farm price increases are transmitted to all levels of the lamb chain faster than farm price decreases. Moreover, the asymmetric effect is greater in the case of the retail price, suggesting that inflation in food prices is not generated by cost increases but by increases in marketing margins. These results seem to indicate that retailers have market power in the lamb market in Spain, as is the case with most perishable products. In fact, as mentioned in Section 2, retailers are much more concentrated than farmers, at least in the case of supermarket and hypermarket chains operating at national level.

Under the third regime (the retail margin is too high), the general pattern shown in Figure 6 is to some extent similar, although with a few differences that are consistent with the pattern of the adjustment coefficients shown in (16). First, in the very short run, the farm price response is higher than in the first regime (recall that $\alpha_{2}^{3}>\alpha_{2}^{1}$ ), while retail price responses are of the same magnitude in both regimes. Second, convergence towards the long-run equilibrium takes place more quickly. Finally, as under the first regime, in the case of the retail price, the adjustment process is positive-asymmetric (lower right panel of Figure 6). However, in the case of the farm prices, we can consider that in the long run the adjustment is symmetric. In fact, in the first two weeks, the adjustment is positive-asymmetric but reverts to negative during the following five weeks before achieving long-run equilibrium. Also under the third regime, the magnitude of the asymmetric effect is higher in the retail price as a consequence of retailers' market power along the lamb marketing chain.

\footnotetext{
${ }^{29}$ Qualitative research on the Spanish lamb chain indicates that after slaughter, it takes 1-2 days for the carcasses to be transported to the retailers. Once there, the product has to be sold on in 4-5 days.
} 
Responses to shocks in retail prices are shown in Figure 7. As in the previous figure, in the upper part the responses of farm and retail prices, in both regimes, to a shock in the retail price are shown, while in the lower part, the Potter measure is also provided for the two regimes. Regime 1 means that the retail margin is too low. Then a positive (negative) shock in the retail price increases (decreases) the retail margin. To restore equilibrium, the farm price should ultimately increase (decrease) and the retail price should decrease (increase). This is what can be seen in Figure 7 (upper left) after about 3-4 weeks. In any case, convergence with the retail price responses is reached after six months. Thus, in the short run retailers benefit from a demand shock as the marketing margin increases substantially.

\section{(Insert Figure 7)}

Farm price responses are also different for negative shocks as compared to positive shocks. Responses to negative shocks are larger in the short run whereas after 14 weeks the opposite occurs. Thus, farm price responses to a shock in the retail price exhibit a cyclical asymmetric pattern in the short run, and become positive-asymmetric in the long run.

Comparing the asymmetric behaviour of both retail and farm prices to demand shocks in the first regime shows that the situation is somewhat different to the supply shock situation represented in Figure 6. In this case, retailers benefit from increasing marketing margins during the first 15 weeks. However, this initial effect is compensated during the following 15 weeks, as the magnitude of the asymmetric effect is greater in the case of the farm price.

Finally, under the third regime (the retail margin is too high), a negative shock in the retail price decreases the retail margin. Then if the retail margin becomes too low that regime 1 applies. To restore equilibrium the farm price is going to increase and the retail price is going to decrease. Contrary to the first regime, responses to both positive and negative shocks are similar while convergence takes place more quickly (10 weeks). Finally, the most interesting result is that it is only in this case (excess supply) that farm and retail price responses to positive and negative demand shocks are symmetric.

\section{$5 \quad$ Conclusions}

This paper has explored the non-linearity in the price transmission mechanism along the lamb marketing chain in Spain. The methodology used involved specifying and estimating a threeregime TVECM. Price reactions in the intermediate regime are not significant, allowing us to 
specify a Band-TVECM. The paper presents the regime-specific long-run equilibrium analysis and short-run dynamics. The results obtained suggest a number of points.

In the long run, prices at both ends of the marketing chain are perfectly integrated, that is to say, any change in either of the prices is fully transmitted to the other. However, in the short run, price behaviour is found to be asymmetric. Market power at the retail level (two thirds of total lamb sales at retail level are located in supermarkets and hypermarkets of which the market share of the top-five is around 74 per cent), product perishability together with accountancy rules and inventory management strategies are possible explanations of the shortrun asymmetric price transmission.

The three-regime threshold error correction model allowed us to fully emphasise the asymmetric nature of the adjustment mechanism, which varies according to the size, and sign of the equilibrium error. The first regime is associated with lower marketing margins while the third is associated higher margins. The short-run dynamics in both regimes are similar although the speed of adjustment is faster when retail margins are higher. This price transmission mechanism is explained by the specific characteristics of the lamb production and consumption in Spain. While production is mainly concentrated during spring, leading to lower farm prices (which, on the other hand, increase along the rest of the year), the highest consumption levels are associated to Christmas Holidays, leading to higher prices for a short period of time. Thus, when farm prices have reached their top and are going to decrease, retail prices are increasing generating lower marketing margins. The opposite takes place after Christmas, generating higher marketing margins. The quick decrease of retail prices after December makes the speed of adjustment faster when retail margins are higher.

In an environment of lower marketing margins, negative (positive) supply shocks squeeze (stretch) the marketing margin. At both ends of the supply chain, responses are always positive-asymmetric, that is, negative supply shocks are transmitted faster than positive shocks. In any case, the magnitude of the asymmetric effect is higher at the retail level, indicating that retailers benefit from increasing marketing margins. On the other hand, positive (negative) demand shocks stretch (squeeze) the marketing margin. Again in this case, at the retail level, positive shocks are more persistent, thus generating positive asymmetries. At the farm level, demand shocks generate, in the long run, positive-asymmetric responses. However, during the first 15 weeks, negative shocks are more persistent, increasing price spreads. 
In a high retail margin situation, the general pattern is somewhat different. First, as mentioned above, responses converge more rapidly to the long-run equilibrium. As in the previous case, retailers benefit from supply shocks, as responses to negative shocks are more persistent than those to positive shocks, generating positive asymmetries in the first 7 weeks. At farm level, the long-run adjustment seems to be symmetric. While in the very short run (two weeks) negative supply shocks are more persistent than positive supply shocks, this is reversed in the following 5 weeks. In any case, as in the price-increasing situation, retailers benefit from higher marketing margins, as the asymmetric effect is higher at the retail level. Finally, positive and negative demand shocks generate symmetric responses at both levels of the marketing chain.

The analysis has focused on vertical price adjustments in the Spanish lamb marketing chain. It can be extended in several directions. First, other meat sectors in Spain with different market structures (different degrees of market integration) or other food sectors with different characteristics (branded products, more processed products, non-perishable products) could be investigated in order to improve our understanding of the price transmission mechanism. Second, further applications to the same sector in other countries with different market structures would allow us to link our results with market power or stock holding policies. Third, taking into account that the methodological approach followed in this paper uses price data only, structural models could be developed in the future, where data availability permits, in order to investigate the main determinants of the evolution of marketing margins. Finally, further refinements from the methodological point of view could be made in the future as new theoretical econometric issues arise in the context of non-linear models in a multivariate framework.

\section{References}

Alderman, H. (1993). Intercommodity Price Transmittal: Analysis of Markets in Ghana. Oxford Bulletin of Economics and Statistics 55(1): 43-64.

Azzam, A. (1999). Asymmetry and Rigidity in Farm-Retail price Transmission. American Journal of Agricultural Economics 81: 525-533.

Balke, N.S. and Fomby, T.S. (1997). Threshold Cointegration. International Economic Review 38: 627-645. 
Balke, N.S., Brown, S.P.A. and Yücel, M.K. (1998). Crude oil and gasoline prices: An asymmetric relationship? Federal Reserve Bank of Dallas, Economic Review, First Quarter: $2-11$.

Banerjee, A.; Dolado, J.J.; Galbraith, J.W. and Hendry, D.F. (1993). Co-integration, Error Correction, and the Econometric Analysis of non-Stationary data. Advanced text in Econometrics, Oxford University Press.

Bettendorf, L. and F. Verboven (2000). Incomplete Transmission of Coffee Bean Prices: Evidence from the Dutch Coffee market. European Review of Agricultural Economics 27: 116.

Boyd, M.S. and Brorsen, B.W. (1988). Price Asymmetry in the U.S. Pork Marketing Channel. North Central Journal of Agricultural Economics 10: 103-109.

Cáceres, J.J. (1996). Contrastes de Raíces Unitarias en Datos Semanales. Estadística Española Vol 141: 139-159.

Chavas, J.P., and Mehta, A. (2004). Price Dynamics In A Vertical Sector: The Case Of Butter. American Journal of Agricultural Economics 86: 1078-1093.

Cowling, K and Waterson, M. (1979). Price-Cost Margins and Market Structure. Economica 43: 267-274.

Doornik, J.A. and Hendry, D.F. (1997). Modelling Dynamic systems using PcFilm 9 for Windows. Timberlake Consulting, London.

Doran, H.E. and Quilkey, J.J. (1972). Harmonic Analysis of Seasonal Data: Some Important Properties. American Journal of Agricultural Economics 54: 646-651.

Elliott, G., Rothenberg, T. J. and Stock, J. H. (1996). Efficient Tests for an Autoregressive Unit Root. Econometrica 64 813-836.

Escribano, A. and Mira, S. (1996). Nonlinear cointegration and nonlinear error-correction models. Working paper, Universidad Carlos III de Madrid.

Franses, P.H. (1991). Model selection and seasonality in time series. Tinbergen Institute series $\mathrm{N}^{\circ}$ 18. Erasmus University. Rotterdam.

Frey G. and Manera M. (2007). Econometric Models of Asymmetric Price Transmission. Journal of Economic Surveys 21: 259-325. 
Gardner, B.L. (1974). The Farm-Retail Price Spread in a Competitive Food Industry. American Journal of Agricultural Economics 57: 383-406.

Goodwin, B.K. (2006). Spatial and Vertical Price Transmission in Meat markets. Paper presented at the Workshop on Market Integration and Vertical and Spatial Price Transmission in Agricultural Markets. University of Kentucky, USA, April.

Goodwin, T.J., Grennes, T.J. and Lee, A. C. (2002). Mechanical Refrigeration and the Integration of Perishable Commodity Markets. Explorations in Economic History Vol. 39, Issue 2: 154-182.

Griffith, G.R. and Piggott, N.E. (1994). Asymmetry in Beef, Lamb and Pork Farm-Retail Price Transmission in Australia. Agricultural Economics 10: 307-316.

Hamilton, G. (1994). Time Series Analysis. Princeton University Press.

Hansen, B.E. (1999). Testing for linearity. Journal of Economic Surveys 13: 551-576.

Hansen, B.E. and Seo, B. (2002). Testing for Two-Regime Threshold Cointegration in Vector Error Correction Models. Journal of Econometrics 110: 293-318.

Houck, J.P. (1977). An Approach to Specifying and Estimating Nonreversible Functions. American Journal of Agricultural Economics 59: 570-572.

Johansen, S. (1988). Statistical Analysis of the Cointegration Vectors. Journal of Economic Dynamics and Control 12: 231-254.

Johansen, S. (1995). Likelihood-based Inference in Cointegrated Vector Autoregressive Models. Oxford University Press, Oxford.

Kapetanios, G. (2003). Threshold Models for Trended Time Series. Empirical Economics 28(4): 268-707.

Kinnucan, H.W. and Forker, O.D. (1987). Asymmetry in the Farm-Retail Price Transmission for Major Dairy Products. American Journal of Agricultural Economics 69: 285-292.

Koop, G., Pesaran, M.H. and Potter, S.M. (1996). Impulse Response Analysis in Nonlinear Multivariate Models. Journal of Econometrics 74: 119-147.

Krolzig, H.M. and Toro, J. (2001). A New Approach to the Analysis of Business Cycle Transitions in a Model of Output and Employment. Department of Economics discussion paper series No. 59, University of Oxford: Oxford. 
Kwiatkowski, D., Phillips, P., Schmidt, P. and Shin, Y. (1992). Testing the Null Hypothesis of Stationarity Against the Alternative of Unit Root. Journal of Econometrics 54: 159-178.

Larue, B. (1991). Farm Input, Farm Output and Retail Food Prices: A Cointegration Analysis. Canadian Journal of Agricultural Economics 39: 335-353.

Lloyd, T. A., McCorriston, S., Morgan, C. W., and Rayner, A. J., (2006). Food Scares, Market Power and Price Transmission: The UK BSE Crisis. European Review of Agricultural Economics 33(2): 119-147.

Lo, C. and Zivot, E. (2001). Threshold Cointegration and Nonlinear Adjustments to the Law of One Price. Macroeconomic Dynamics 5: 533-576.

London Economics (2004). Investigation of the determinants of farm-retail price spreads. Report prepared for the Department for Environment, Food and Rural Affairs.

McCorriston, S., Morgan, C. W. and Rayner A. J. (2001). Price Transmission: The Interaction Between Market Power and Returns to Scale. European Review of Agricultural Economics 28: $143-159$.

Meyer, J. and Von Cramon-Taubadel, S. (2004). Asymmetric price transmission: a survey. Journal of Agricultural Economics 55: 581-611.

Ng, S. and Perron, P. (2001). Lag Length Selection and the Construction of Unit Root Tests with Good Size and Power. Econometrica 69: 1519-1554.

Peltzman, S. (2000). Prices Rise Faster than they fall. Journal of Political Economy 108(3): 466-502.

Pesaran, M.H. and Shin, Y. (1996). Cointegration and Speed of Convergence to Equilibrium. Journal of Econometrics 71: 117-43.

Potter, S.M. (1995). A Nonlinear Approach to U.S. GNP. Journal of Applied Economics 10: 109-125.

Reagan, P.B. and Weitzman, M.L. (1982). Asymmetries in Price and Quantity Adjustments by the competitive Firm. Journal of Economic Theory 27: 410-420.

Sexton, R., Zhang, M. and Chalfant, J. (2003). Grocery retailer Behavior in the Procurement and sale of Perishable Fresh Produce Commodities. Contractctors and Cooperators Report \#2. Economic Research Service, USDA. 
Starleaf, D.R., Meyer, W. H. and Womack, A. (1985). The Impact of Inflation on the Real Income of U.S. Farmer. American Journal of Agricultural Economics 67: 384-389.

Tiao, G.C. and Box, G.E. (1981). Modeling Multiple Time Series Applications. Journal of American Statistical Association 76: 802-816.

Tsay, R. (1998). Testing and modelling multivariate threshold models. Journal of the American Statistical Association 93(1): 1188-1202.

Ulloa, R. (2005). Análisis del posicionamiento de la marca genérica Ternasco de Aragón con Indicación Geográfica Protegida, desde el punto de vista del consumidor. Unpublished PhD Thesis. University of Zaragoza, September.

Vavra, P. and Goodwin, B.K. (2005). Analysis of Price Transmission Along the Food Chain. OECD Working Papers No. 3(11).

Von Cramon-Taubadel, S. (1998). Estimating Asymmetric Price Transmission with the Error Correction Representation: An Application to the German Pork Market. European Review of Agricultural Economics 25: 1-18.

Ward, R.W. (1982). Asymmetry in Retail, Wholesale and Shipping Point Pricing for Fresh Vegetable. American Journal of Agricultural Economics 64: 205-212.

Weldegebriel, H. T., (2004). Imperfect Price Transmission: Is Market Power Really to Blame? Journal of Agricultural Economics 55: 101-114.

Wohlgenant, M.K., (2001). Marketing Margins: Empirical Analysis. In Bruce Gardner and Gordon Rausser (eds), Handbook of Agricultural Economics, Volume 1, Amsterdam: Elsevier Science B.V. Chapter 16: 934-970.

Wolfffram, R. (1971). Positivistic Measures of Aggregate Supply Elasticities: Some New Approaches - Some Critical Notes. American Journal of Agricultural Economics 53: 356359. 
Table 1. Tests for non-linearities in price adjustments

\begin{tabular}{|l|l|l|}
\hline & $\mathrm{LR}_{1,3}{ }^{\mathrm{a}}$ & $\mathrm{LR}_{2,3}{ }^{\mathrm{b}}$ \\
\hline Test statistic & 89.72 & 63.91 \\
\hline FR critical value $(5 \%)^{\mathrm{c}}$ & 43.46 & 40.72 \\
\cline { 2 - 3 } PR critical value $(5 \%)^{\mathrm{d}}$ & 51.55 & 48.29 \\
\hline Threshold parameters & $\hat{\lambda}=(-0.0679,-0.0065)$ & \\
\hline
\end{tabular}

a The $\mathrm{LR}_{1,3}$ tests the null of linearity against the alternative of a three-regime TVECM (Lo and Zivot, 2001).

$\mathrm{b}$ The $\mathrm{LR}_{2,3}$ tests the null of a two-regime TVECM against the alternative of a three-regime TVECM (Lo and Zivot, 2001).

c Critical values are obtained using the fixed regressor (FR) bootstrapping technique (Hansen and Seo, 2002).

d Critical values are obtained using the parametric residual (PR) bootstrap algorithm (Hansen and Seo, 2002). 
Table 2. Estimated parameters of the $\mathrm{TVECM}_{3}{ }^{\mathrm{a}}$

\begin{tabular}{|c|c|c|c|}
\hline & $\begin{array}{l}\text { Regime } 1^{\mathrm{b}} \\
\omega_{t-1}(\hat{\beta})<-0.0679\end{array}$ & $\begin{array}{l}\text { Regime } 2^{\mathrm{b}} \\
-0.0679 \leq \omega_{t-1}(\hat{\beta}) \leq-0.0065\end{array}$ & $\begin{array}{l}\text { Regime } 3^{\mathrm{b}} \\
\omega_{t-1}(\hat{\beta})>-0.0065\end{array}$ \\
\hline$\left(\begin{array}{l}\alpha_{1}^{\mathrm{i}} \\
\alpha_{2}^{\mathrm{i}}\end{array}\right)$ & $\left(\begin{array}{c}-0.053 \\
(0.021) \\
0.026 \\
(0.031)\end{array}\right)$ & $\left(\begin{array}{c}0.003 \\
(0.090) \\
-0.0091 \\
(0.023)\end{array}\right)$ & $\left(\begin{array}{c}-0.054 \\
(0.023) \\
0.104 \\
(0.041)\end{array}\right)$ \\
\hline $\begin{array}{l}\% \text { of } \\
\text { observations }\end{array}$ & 33.33 & 38.33 & 28.33 \\
\hline \multicolumn{4}{|c|}{ Misspecification tests } \\
\hline \multicolumn{2}{|l|}{ Farm prices } & \multicolumn{2}{|l|}{ Retail prices } \\
\hline $\mathrm{BG}(1)-\mathrm{FP}^{\mathrm{c}}$ & 2.59 & $\mathrm{BG}(1)-\mathrm{RP}$ & 0.44 \\
\hline $\mathrm{BG}(52)-\mathrm{FP}^{\mathrm{c}}$ & 1.46 & BG(52)-RP & 1.13 \\
\hline $\mathrm{ARCH}(1)-\mathrm{FP}^{\mathrm{c}}$ & 3.84 & ARCH(1)-RP & 3.32 \\
\hline $\mathrm{ARCH}(52)-\mathrm{FP}^{\mathrm{d}}$ & 3.76 & $\mathrm{ARCH}(52)-\mathrm{RP}$ & 3.86 \\
\hline $\mathrm{JB}-\mathrm{FP}^{\mathrm{e}}$ & 3.04 & JB-RP & 4.02 \\
\hline
\end{tabular}

a. Values in parentheses are standard deviations.

b. $\omega_{t-1}(\hat{\beta})=R P-F P-0.635$.

c. BG(i) is the Breusch-Godfrey test for autocorrelation of order i (critical value at the 5\% significance level is 3.84).

d. ARCH (i) is the Engle test for conditional heteroscedasticity of order i (critical value at the $5 \%$ significance level is 3.84 ).

e. JB is the Jarque-Bera test for normality (critical value at the 5\% significance level is 5.99). 
Figure 1. Farm and retail prices for lamb in Spain ( $€ / \mathrm{kg}$ of equivalent carcass weight) (19962002)

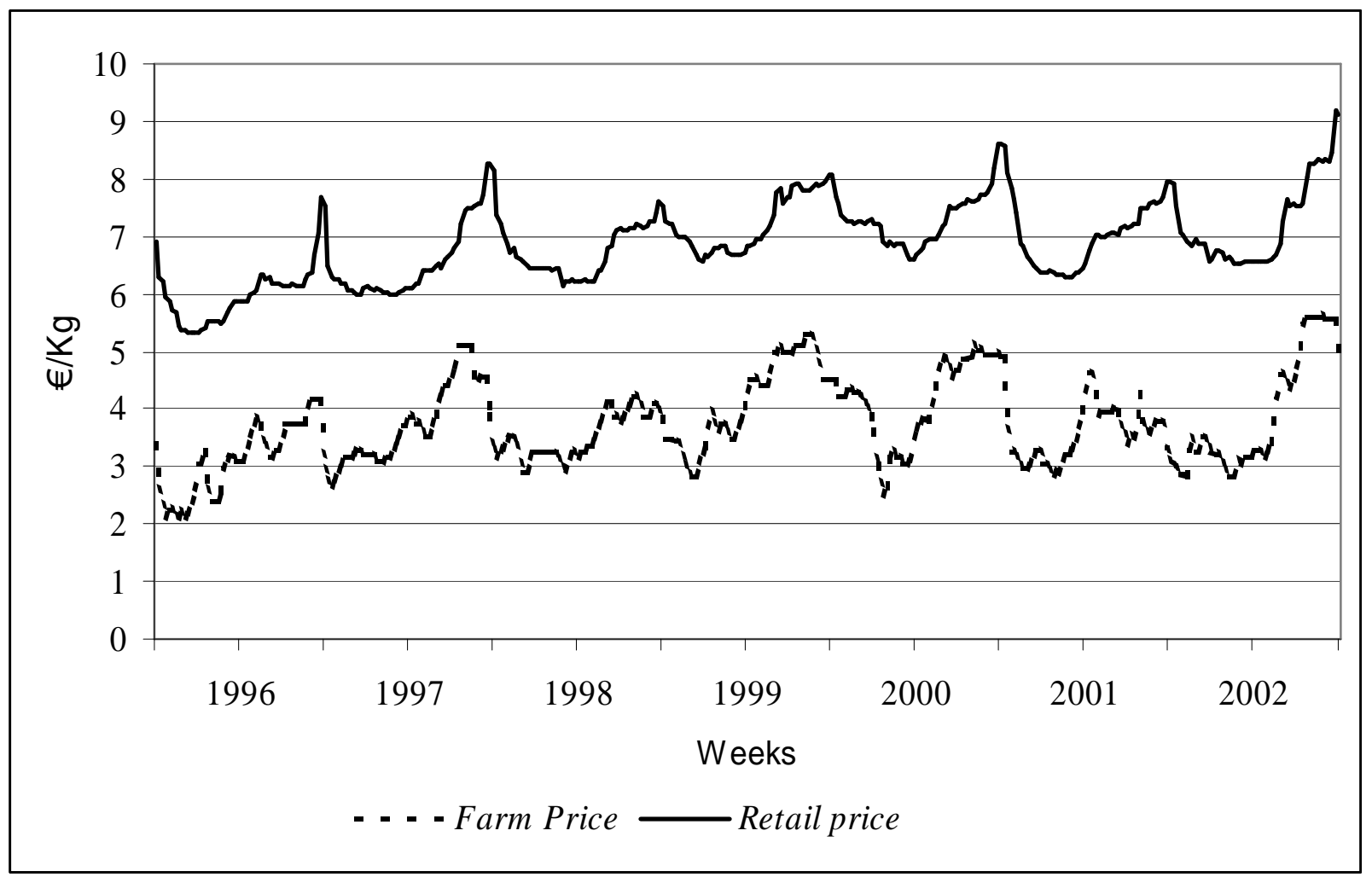

Source: MAPA, ICE and own calculations 
Figure 2.Evolution of the retail marketing margin (1996-2002)

a) RP-FP, absolute values ( $€ / \mathrm{kg})$

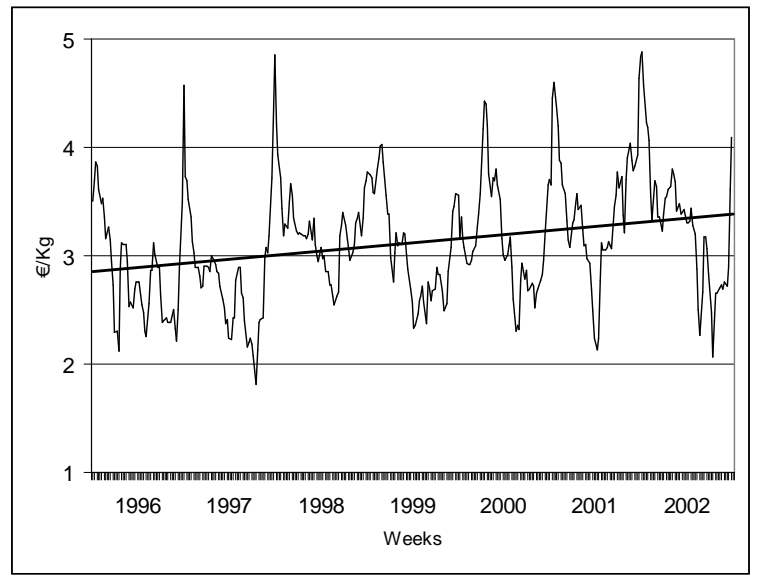

b) $\mathrm{RP} / \mathrm{FP}$, percentage of farm price

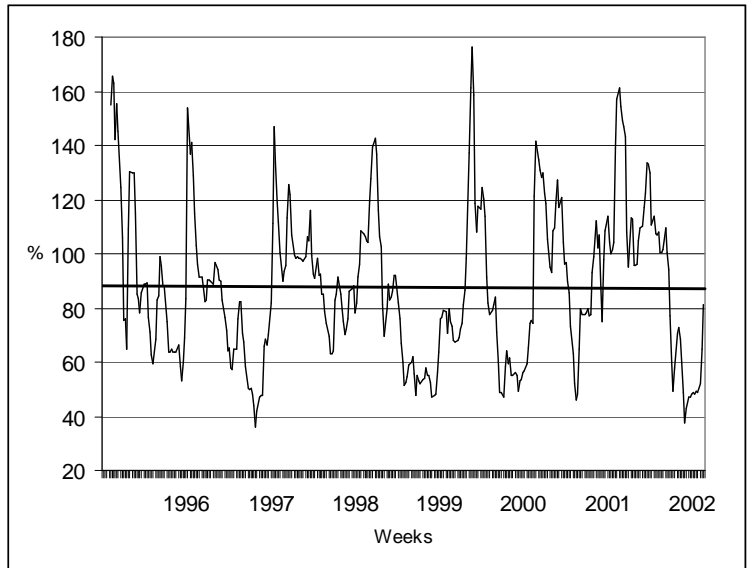

Note: $\mathrm{RP}=$ retail price $; \mathrm{FP}=$ farm price 
Figure 3. Behaviour of farm and retail prices when marketing margins are increasing or decreasing (average weekly percentage changes during 1996-2002)

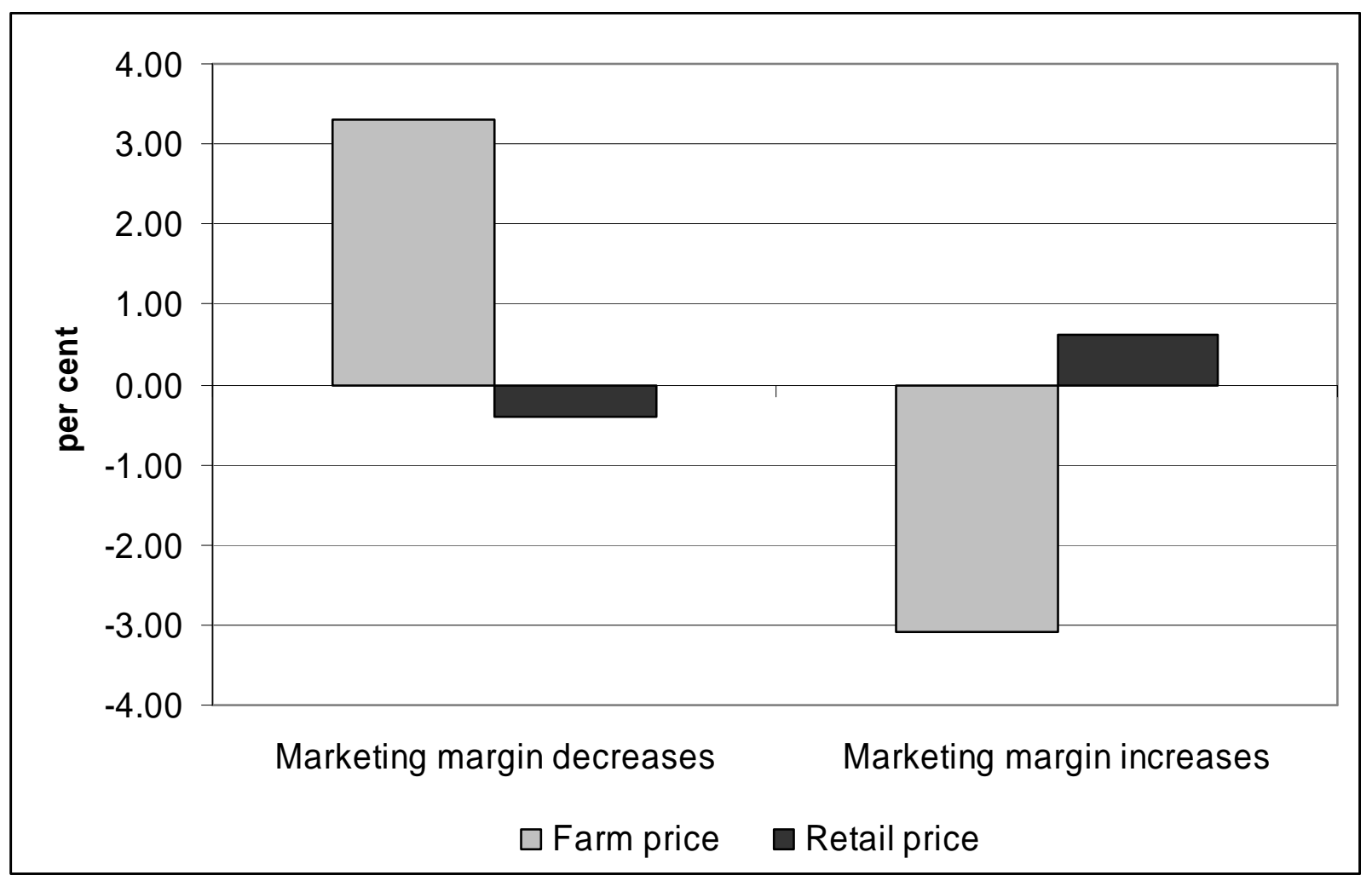


Figure 4. Classification of prices evolution under the three regimes $(€ / \mathrm{kg})$

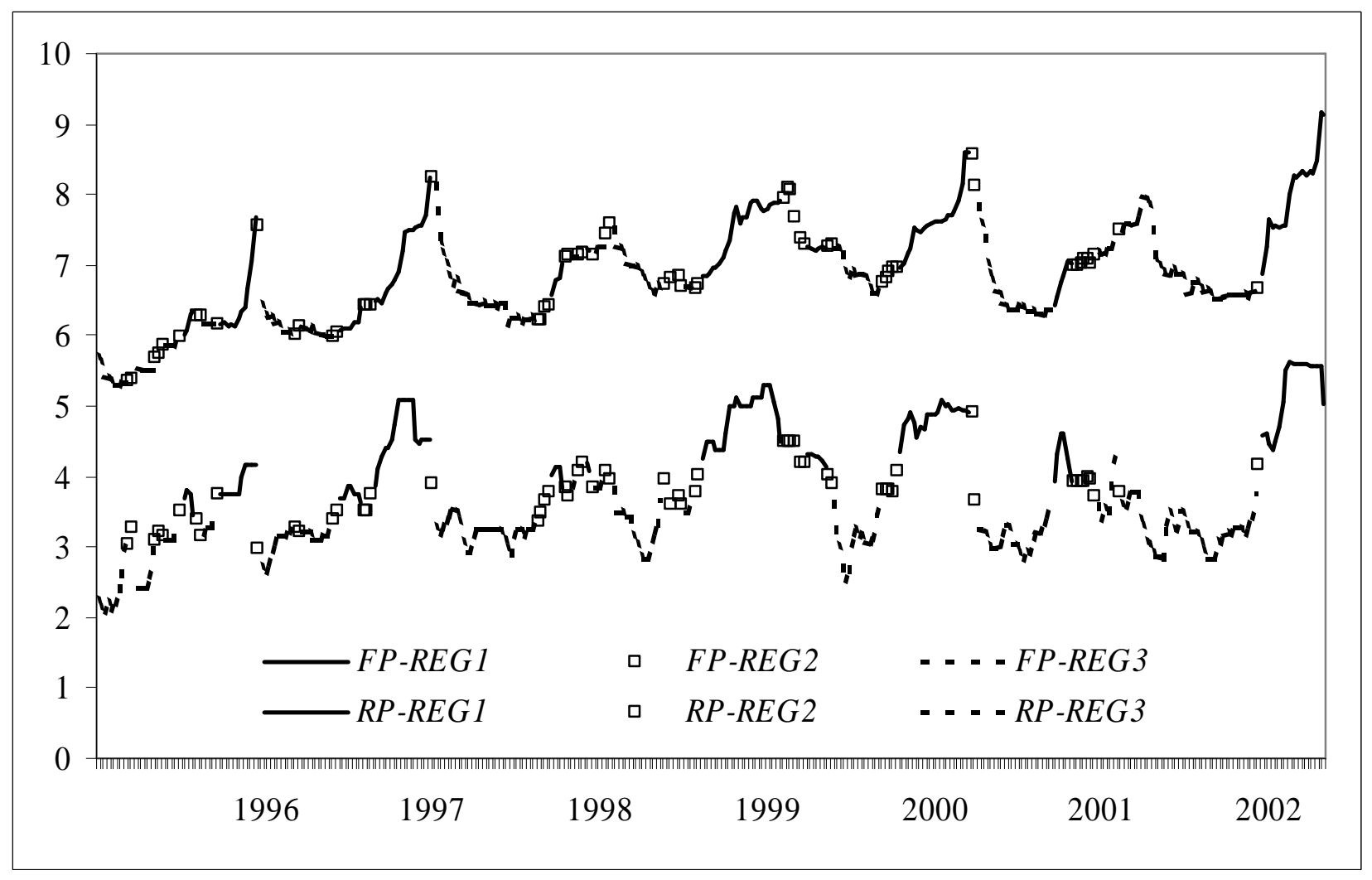


Figure 5. Persistence Profiles to a $1 \%$ positive and negative shock in the cointegrating vector under the two regimes

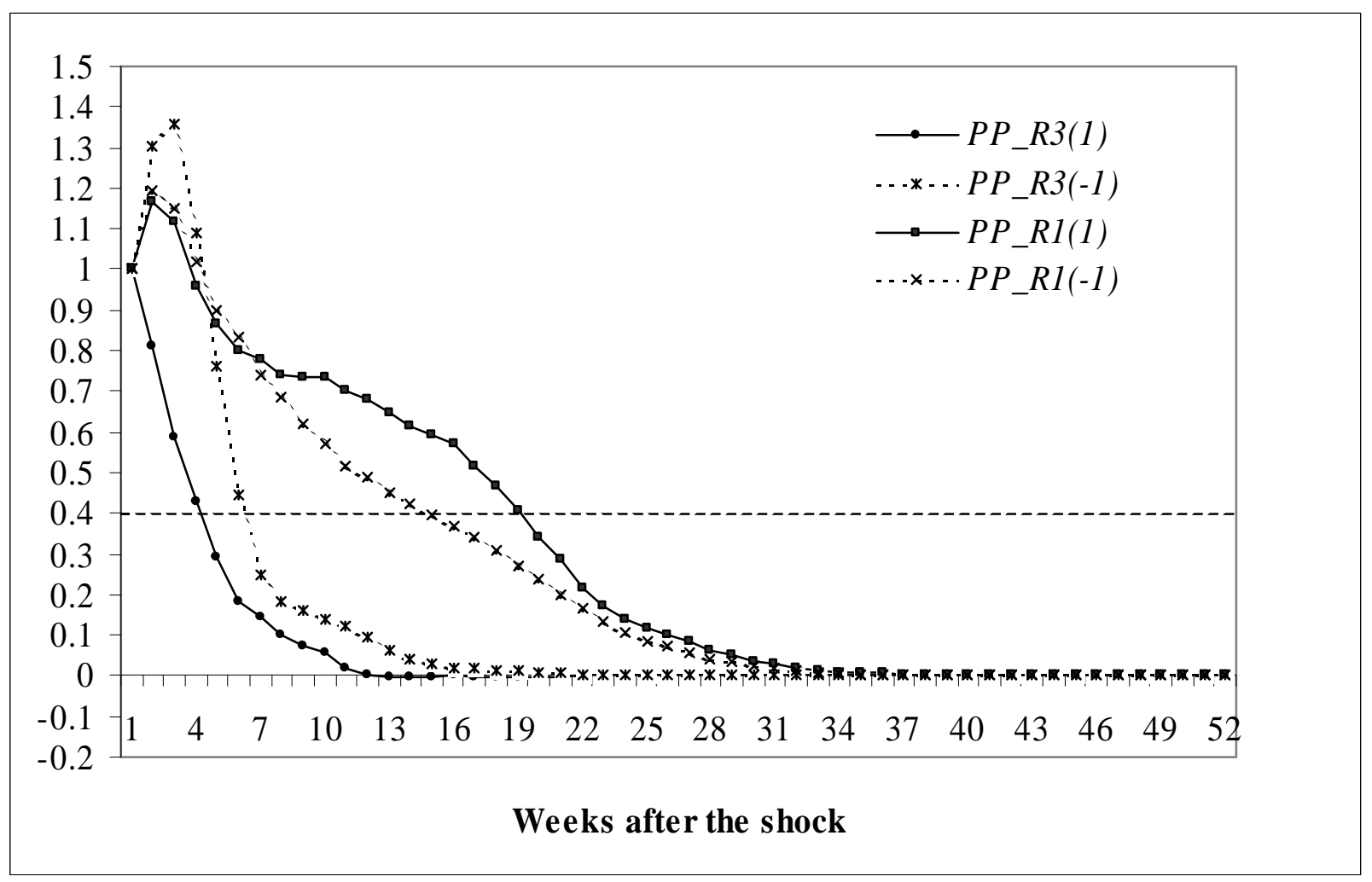

Note: PP_Ri $(\delta)$ indicates the Persistence Profile in the $\mathrm{i}$-th regime $\mathrm{i}(\mathrm{i}=1,3)$ to a system-wide shock $\delta(\delta=1,-1)$ 
Figure 6. Impulse response functions to a positive and negative shock in FP under the two regimes ${ }^{1}$

Shock in FP (Regime 1)

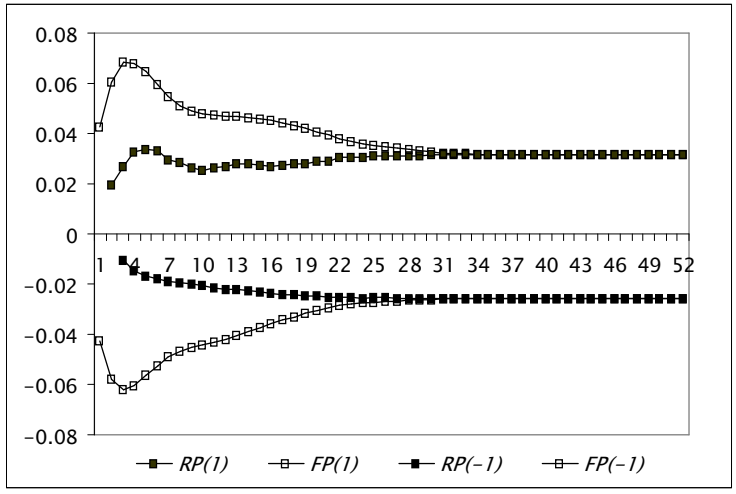

Asymmetric responses (Regime 1) Shock in FP

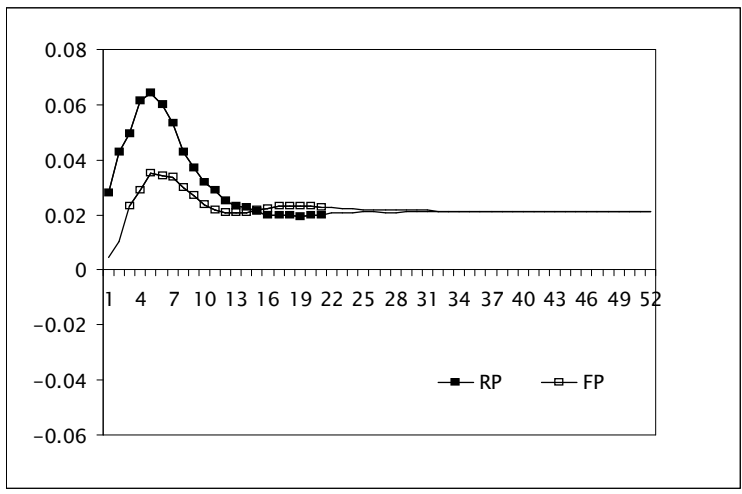

Shock in FP (Regime 3)

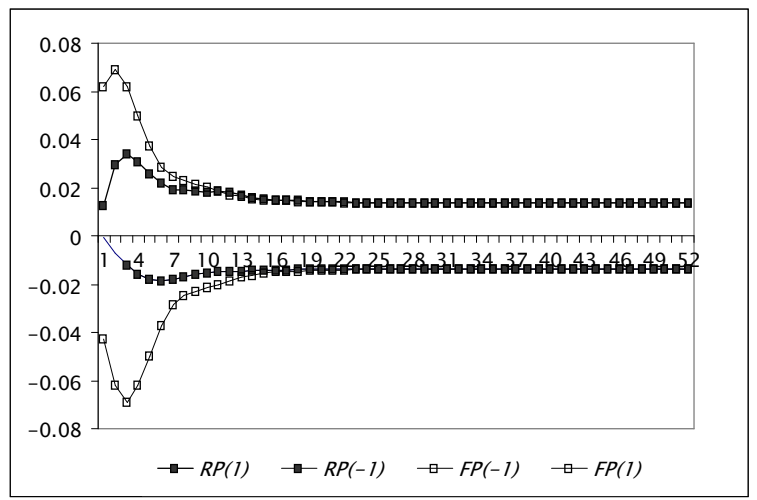

Asymmetric responses (Regime 3) Shock in FP

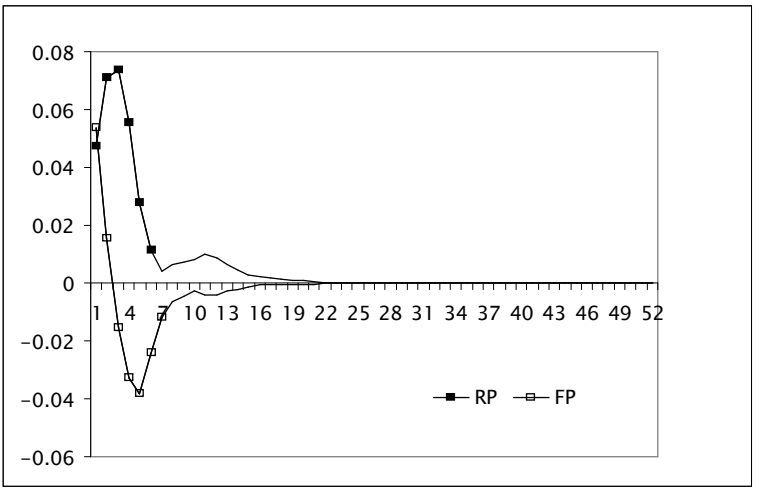

Note that $\square(\mathbf{a})$ indicates that the farm (retail) response is significant at the $5 \%$ level

${ }^{1}$ In the upper part only impulse responses for $\delta= \pm 1$ are shown, while in the lower part, the Potter's measure is provided adding the responses for $\delta= \pm 1$ and \pm 2 . 
Figure 7. Impulse response functions to a positive and negative shock in RP under the two regimes ${ }^{1}$

Shock in RP (Regime 1)

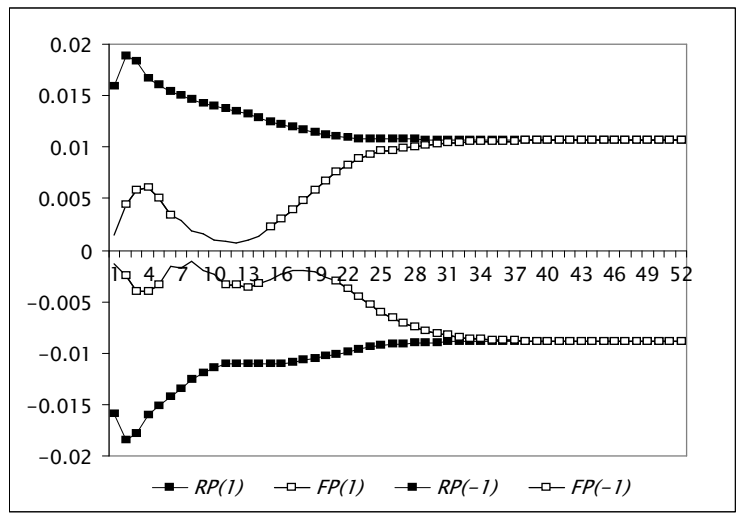

Asymmetric responses (Regime 1) Shock in RP

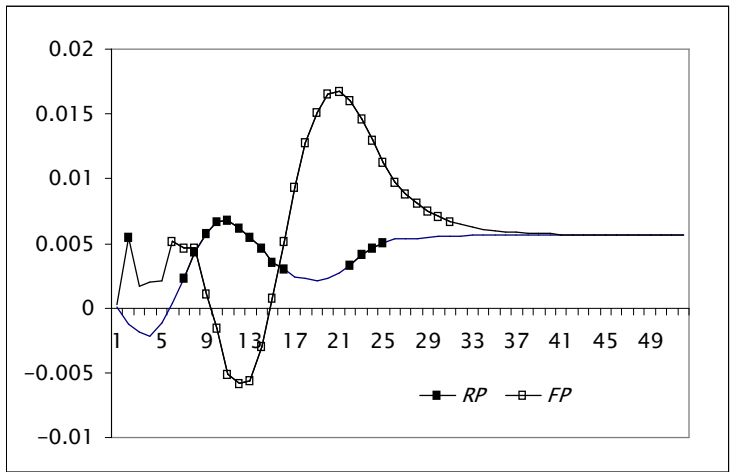

Shock in RP (Regime 3)

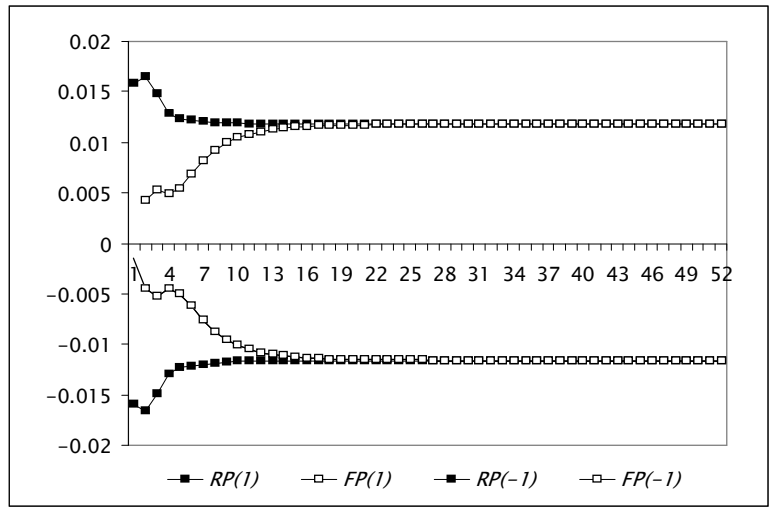

Asymmetric responses (Regime 3) Shock in RP

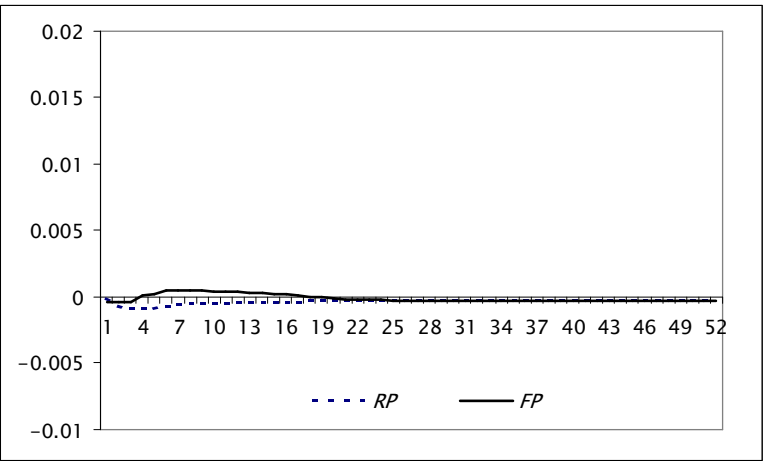

Note that $\square(\mathbf{\square})$ indicates that the farm (retail) response is significant at the $5 \%$ level

${ }^{1}$ In the upper part only impulse responses for $\delta= \pm 1$ are shown, while in the lower part, the Potter's measure is provided adding the responses for $\delta= \pm 1$ and \pm 2 . 